\title{
Changes in occupational profiles and occupational health service
}

\section{DOI: $\underline{\text { http://doi.org/10.26758/8.1.18 }}$}

\author{
Alina Ferdohleb
}

Nicolae Testemitanu State University of Medicine and Pharmacy, Department of Management and Psychology; National Center of Public Health, Scientific laboratory of Occupational health; Chisinau, Republic of Moldova

Address correspondence to: Alina Ferdohleb, bld. Stefan cel Mare si Sfant 196-B, Chisinau, Republic of Moldova; e-mail: alina.ferdohleb@gmail.com

\begin{abstract}
Objectives. Changes in the economy and occupational profile, implementation of new technologies and fragmentation of tasks and work processes justify the urgent needs in specialized occupational health and basic services. The national economy of the Republic of Moldova used to be based on the agricultural sector, two-thirds of the workers being employed in agriculture, while at present this country is undergoing changes in the occupational profile of the agricultural workers. As the total number of employees was reduced twice, the office workers, public workers, and others experienced a growing trend.

Material and methods. Cross-descriptive, retrospective, sociological (questionnaire for hygienist doctors from territorial public health centers), and analytical-descriptive research of national occupational profile in the dynamics of 15 years was conducted. Approval of the ethics committee and informed respondent consent were obtained. There are presented the remote results of 61 hygienist doctors and 53 expert doctors who activated in the security and health services from the Republic of Moldova.

Results. A demographic decline among the working age population was registered (from $63.78 \%$ in 2000 to $59.58 \%$ in 2015); there was also a decrease in the diagnosis of occupational diseases at early stages (0 cases 2014, 2015, 2016), which caused a 1.5-time increase of disabilities in the working population during the last years. We should also mention the 2.5 times rise of the percentage of employees working in harmful and inadequate sanitary conditions. The results of the inquiring the occupational health specialists justified the necessity: to categorize the place of work depending on the branch of the national economy; to elaborate tools to supervise and monitor the occupational health services; to strengthen medical statistical tools in occupational health care; to show the main causes of illness.

Conclusions. Currently, the results of changes in the occupational profile are caused by: the absence of an interdepartmental strategic plan in the field of occupational health; the small number of businesses where health services are provided; lack of specialized indicators for monitoring occupational health; a low number of doctors specializing in occupational medicine; lack of motivation from the employer and the employee to establish the diagnosis of occupational disease; the phenomenon of high migration of the working-age population; the lack of a national electronic medical register for medical examination of the employees with occupational diseases.
\end{abstract}

Keywords: occupational profile; occupational disease; performance indicators; working age population. 


\section{Introduction}

Occupational Health Services (OHS) developed alongside with other social protection measures as a response to provocations of the industrial revolution and demographic changes associated with XXI century (Rantanen and Kim/WHO, 2012). These were perceived as necessary and often initiated by industry. Their organization and tasks are defined tripartite international labor law (employee, employer and syndicates/patronages).

The practice of $\mathrm{OH}$ appeared from the social changes of the industrial revolution and in some cases, is seen as an integral component of a successful business. Still, the access to specialized advice from OHS is mostly limited to employees from big enterprises. Challenges associated with Public Health because of a growth of non-communicable diseases and aging of population will lead to changes in national health systems and integration of new $\mathrm{OH}$ systems (Michalak, 2002).

The growth of world commerce and concurrency based on new technologies changed not only the professional dangers but also lead to the considerate fortification of the subject in the legislation. Implementation and adaptation of these acts need a change from occupational health services, as well from employer/boss. As a result, the current changes in the occupational profile make a beneficial contribution to the development of healthy and productive work conditions and social-economic stability of the country (Godderis, et al., 2004).

Moldova continued on large-scale the socioeconomic reform since the declaration of independence. Despite major changes, which happened during the transition period, of more than 25 years, the economic stability was achieved, GDP growth is moderate, with a reasonable level of unemployment $(4.2 \%)$. Long-term prospects are, however, affected by/correlated with the economic income of migrant workers (which leads to high economic consumption and trade imbalance) but this does not affect the national occupational profile/structure (structures in the national economy, labor productivity in Moldova).

At present, the health of employees working in unfavorable and harmful working conditions is not sufficiently monitored by the occupational health services system in the Republic of Moldova. It is one of public health specialists' concerns in the context of the assessment of occupational risk factors and their influence on the state of health. Despite the progress made in many branches of the Moldavian national economy (agriculture, construction, transport, furniture industry, etc.), the occupational environment continues to present a real danger to the health of employees.

The health assessment does not take into account the employee's daily occupational exposure to the workplace, but only the current situation. The lack of a specialized system in studying and evaluating the relationship between occupational risk factors in the occupational environment and workers' health at the initial/pre-morbid stage allow neither to monitor the health status and the conditions and harmful factors to which workers are exposed, nor, as a result of these investigations, to elaborate the intersectoral prevention measures.

On the other hand, one of the objectives of similar research is to describe opportunities for national profiles supervision (Godderis et al., 2014). Consolidation of occupational health services system will have an important impact not only on public health but also on national economy (Harrison and Dawson, 2016). 


\section{Materials and methods}

In the present research, a transversal-descriptive, sociological analysis of the population able to work was performed. The employees were analyzed depending on their status: official employees, independent workers, unpaid family workers, employers and cooperative members, occupied branch of national economy, as a part of the analytical-descriptive research of occupational national profile in the dynamics of 15 years.

The paper's aim is to describe the "update" of occupational safety and health profile in the Republic of Moldova (***International Labour Organization \& Ministry of Labour, Social Protection and Family of the Republic of Moldova, 2011). The study involved a broad literature research combined with an investigation of the existing methods of reporting and description of the occupational profiles, depending on the country. The field of occupational health takes priority both in the national economy as well in the health of the nation (Macdonald and Sanati 2010). From the literature review, 27 occupational profiles were obtained. Feasibility studies were performed in the same manner in the developed countries, EU countries, neighboring countries, and post-soviet countries: Albania, 2007; Armenia, 2007; Azerbaijan, 2002; China, 2012; India, 2011; Montenegro, 2007; Romania, 2007; Serbia, 2007; the Federation of Bosnia and Herzegovina, 2007; the former Yugoslav Republic of Macedonia, 2008; the Kyrgyz Republic, 2008; the Leningrad Region, 2008; the Murmansk Region, 2009; the Republic of Bulgaria, 2007; the Republic of Croatia, 2007; the Republic of Georgia, 2003, 2008; the Republic of Karelia, 2009; the Republic of Kazakhstan, 2008; the Republic of Tajikistan, 2008; the Republic of Uzbekistan, 2008; the Republika Srpska, 2007; Ukraine, 2007, 2010, 2012.

Our paper is based on the method of describing the occupational profile used in Finland (***Ministry of Social Affairs and Health of Finland, 2006) and Germany (Froneberg and Timm/WHO, 2012). The reasoning behind the selection was the high-ranking positions of these countries in the lists, taking into account the organization of occupational health services, and because of the similarity in health insurance system with the Republic of Moldova.

Additionally, the sociological - qualitative stage (questionnaire for hygienist doctors from territorial public health centers) was also performed as part of the research.

The results of the inquiring were processed with Microsoft Excel and SPSS-21; arithmetic mean (M), the weighted average (P), mean arithmetic error $(\mathrm{m})$, non-parametric tests $(\mathrm{t}, \mathrm{p}, \mathrm{SD}$ and soon) were calculated for validation and according to the advanced hypothesis.

In this research, the fundamental ethical research principles of the Helsinki Declaration have been respected. The hygienist doctors/respondents gave informed consent for enrollment in the study.

\section{Results}

Determination and systematization of a set of epidemiological and performance indicators in the anthropological research are very up-to-date. Electronic report of data can be used by OHS with the aim of supervision and prevention (Michalak J., 2002; Macdonald and Sanati 2010). Afterward, the selected data can serve as indicators for the exposure and prevention of risks and contribute to the evaluation of the performance of occupational health services providers (Turcanu et al., 2012).

According to the database of the National Bureau of Statistics of the Republic of Moldova (available at: www.statistica.md ), on January 1, 2017, the entire population was 3,550,852, out of 
which: $48.08 \%$ were men $(1,707,363$ million) and 51.92\% women $(1,843,486) ; 42.72 \%(1,516,813)$ urban inhabitants and $57.28 \%(2,034,039)$ rural inhabitants, respectively.

The "life expectancy" index in 2016 was 72.17 years, depending on sex -68.14 years for men and 76.15 years for women - and on the place of residence - 75.00 years for the urban population and 70.34 years for the rural population. In contrast, the "demographic burden" index in 2016 was 49.6 persons per republic, indicating a decrease in the working age population and a growth of population besides the working age.

Thus, at 1 January 2017, the working-age population was 2,313,927, which represents $65.17 \%$ of the country's population.

And the population that is economically active and of working age is $35.84 \%(1,272,800)$, of which: $50.33 \%$ men $(640,600)$ and $49.67 \%$ women $(632,200)$. The total adult, working-age population in 2012 was 243.2 million. Out of this total population, 142.4 million were classified as employed and 12.5 million were classified as unemployed.

The remaining the population economically active is $35.84 \%$ cases. On the other hand, the population economically inactive is $48.24 \%(1,712,700)$ (see Figure 1).

Figure 1. Occupational profile of the Republic of Moldova on January 1, 2017.

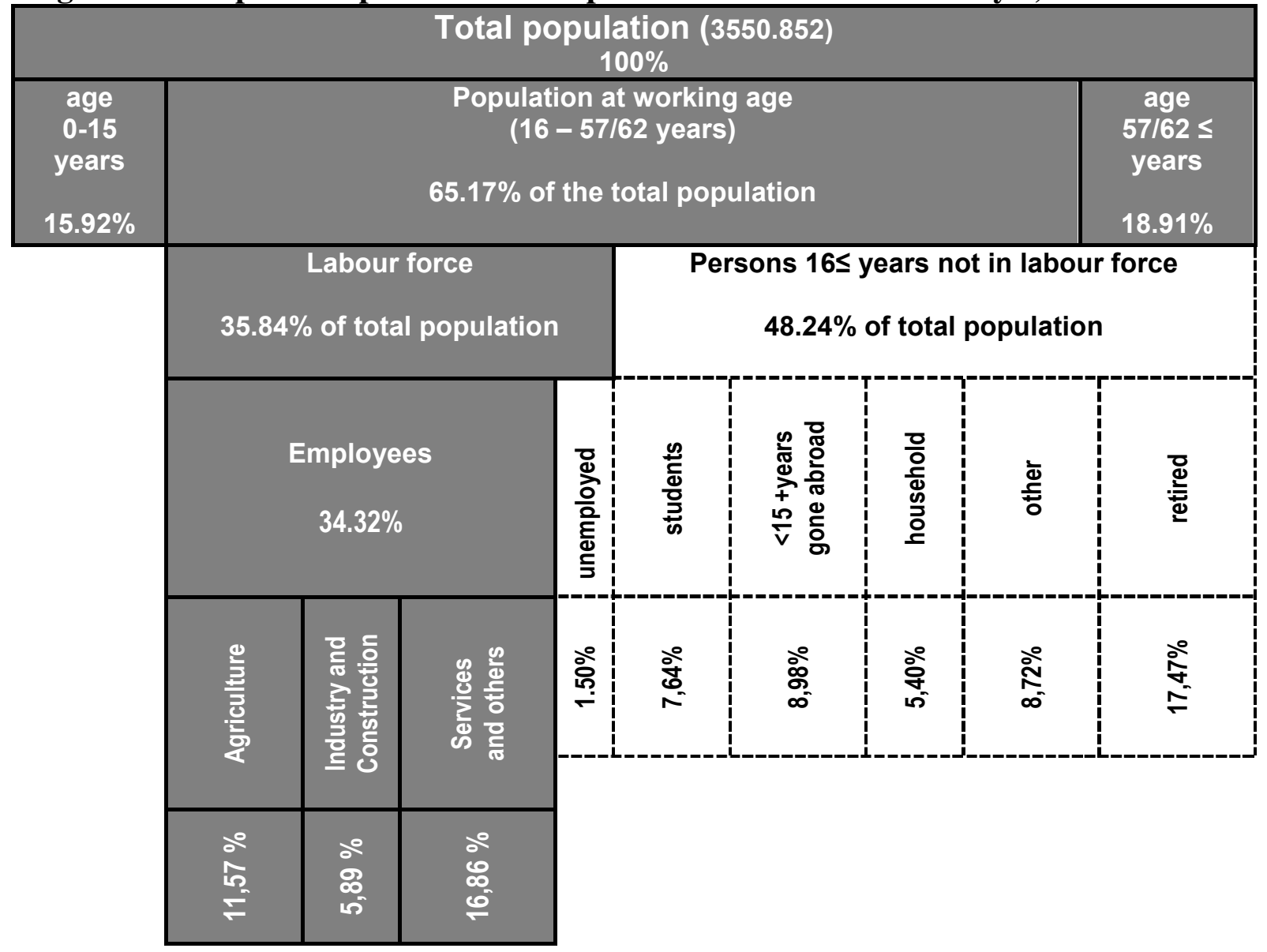

Thus, the share of the unemployed in the country is $4.2 \%(53,300$ of persons), and $1.5 \%$ of the economically active population, respectively. On the other hand, the share is higher $-6.0 \%$ in urban localities compared to rural localities - 2.6\%. Subsequently, we analyzed the unemployment phenomenon by sex, where men's share is $5.5 \%$ and women's $-2.9 \%$, respectively. 
The distribution of the occupational profiles by economic branch is as follows:

- Agriculture, hunting economy and fish farming - $11.57 \%$ of the population $(410,900)$;

- Industry $-4.17 \%$ of the population $(148,100)$;

- Construction $-1.72 \%$ of the population $(60,900)$;

- Wholesale and retail trade; Hotels and restaurants - 6.29\% $(223,500)$;

- Transport and Communications $-2.15 \%$ of the population $(76,200)$;

- Public administration; Education; Health and social assistance - $6.29 \%$ of population $(223,500)$;

- Other activities $-2.82 \%$ of the population $(100,300)$.

It is important to note the significant decrease in number of the working age population over the past 15 years (from $63.78 \%$ in 2000 to $59.58 \%$ in 2015). Promoting 'worthy work for all ages' policy and a gradual increase in the retirement age for men and women might have helped to avoid or minimize the shortages in human resources in some areas of the national economy.

When analyzing absolute data, in the agricultural sector, the number of employees has decreased twice (from 770.4 thousand in 2000 to 381.9 thousand in 2015). Similarly, the number of employees in the industry decreased 1.14 times (from 166.1 thousand in 2000 to 145.6 thousand in 2015). On the other hand, we see some 1.5 times increase in construction field (from 44.4 thousand in 2000 to 65.4 thousand in 2015), as well as in the "wholesale and retail, hotels, restaurants" sector (from 165.3 thousand in 2000 to 189.6 thousand in 2015).

Figure 2. Occupational profile depending on national economy field, \%.

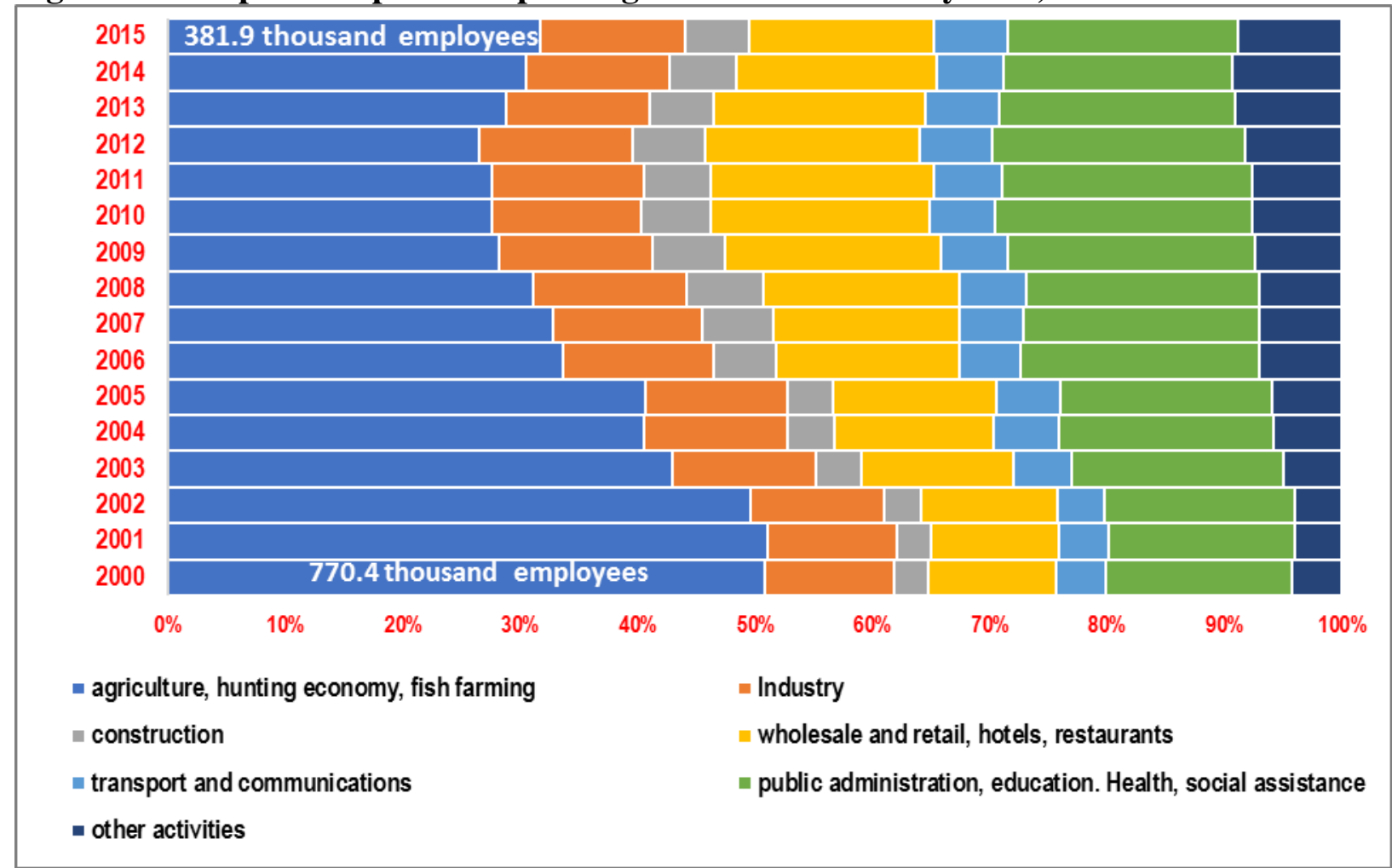

In the next stage, the analysis of the occupational profile was carried out according to the distribution quotas of employees in the national economy.

The trend shows an increase in the former and a steady decline in the latter. Industry $(13.0 \%)$ is in slight growth and construction $(5.7 \%)$ relatively stable. The proportion of public sector employment is relatively high but declining. The share of informal employment is officially $28 \%$, 
but there are estimates referring to as high as 30-50\% share of informal employment if all people participating in work life are counted (Figures 2 and 3). The informality may also explain partly the low formal labor participation rate figures.

The occupational structures are determined by the size of the economic sectors. A series of job sectors - agriculture, forestry, manufacturing, and construction - that absorb almost half of the entire workforce continue to represent high-risk areas regarding the traditional occupational safety and health.

The other half of workforce, such as health workers, workers in trade, hotel, and restaurant occupations, is exposed to the typical occupational health problems of service occupations, ergonomic problems, psychological stress and time pressure and sometimes violence caused by clients. Thus, the Moldavian occupational health services have to be able to respond to both the risks of traditional work and stresses of the so-called new work life.

The distribution of the occupational profiles by the status of the working person (employee, self-employed, unpaid family worker, business owner, member of an agricultural cooperative society) is graphically represented in Figure 3.

Figure 3. Occupational profile according to the employees' statute, $\%$.

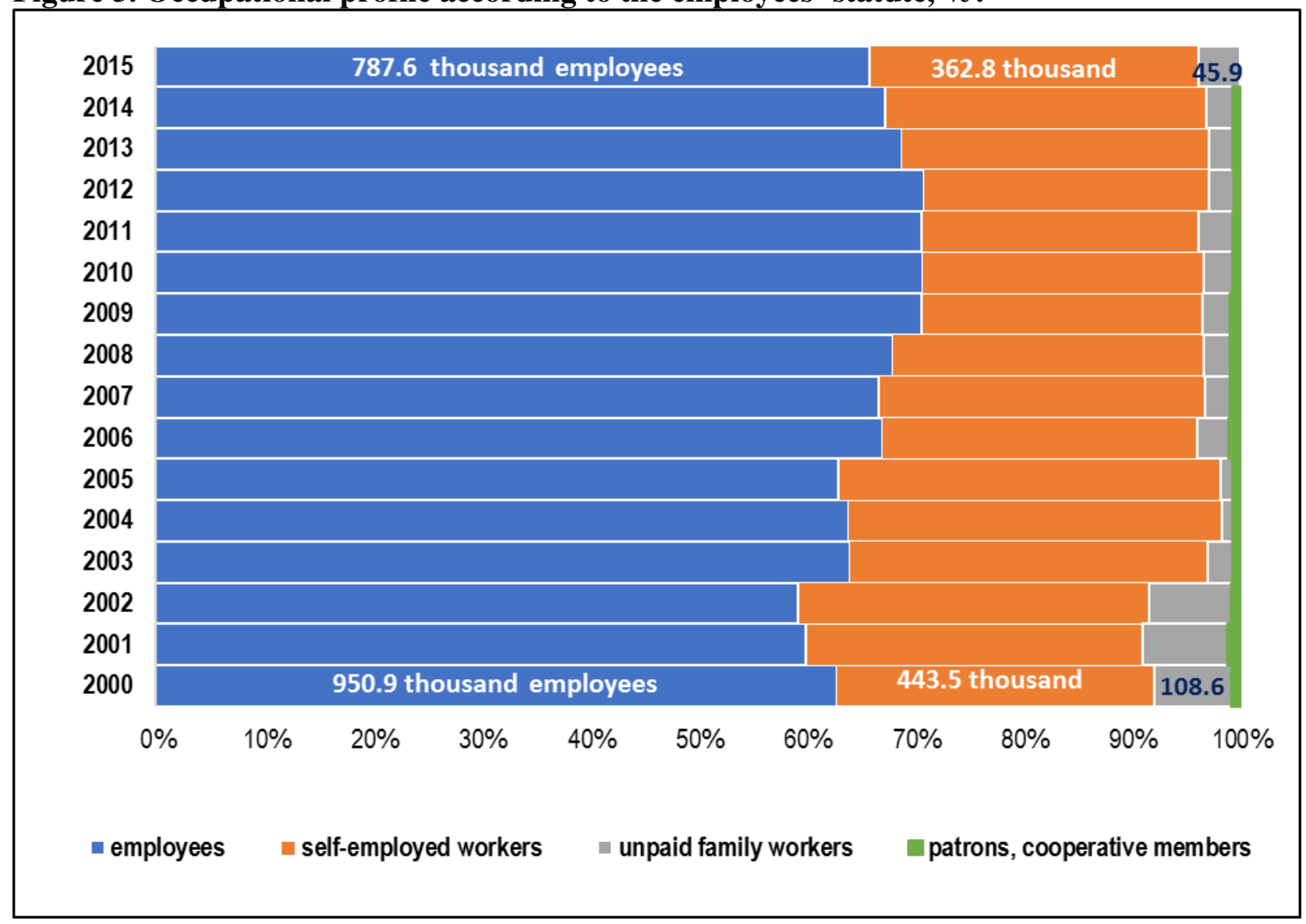

According to the distribution of persons employed in economic activities, 441.0 thousand persons (34.7\% of the total number of employed persons) are employed in the agricultural sector. Of these, $46 \%$ (or $16.1 \%$ of the total number of employed persons) are those engaged in the production of agricultural products exclusively for their own consumption. As compared to 2016, the number of employees in agriculture decreased by 56.5 thousand, or by $11.4 \%$. 
829.2 thousand persons were employed in non-agricultural activities, $2.3 \%$ more than in 2016. The share of persons employed in industry constituted $11.9 \%(11.3 \%$ - 2016) and construction - 5.4 (5.1\% - 2016). The number of persons employed in industry increased by $2.8 \%$ compared to the same quarter of the previous year, and in construction by $2.2 \%$. There were $48.0 \%$ of all employed persons in the services sector, their share recording an increase compared to 2016 $(45.6 \%)$.

By ownership criteria, $75.9 \%$ of the employed population worked in the private sector and $24.1 \%$ in the public sector. The structure of the employed population, according to the professional status, reveals that the share of the employees constituted $63.0 \%$ of the total.

Undeclared work among employees constituted 6.5\%, recording a decrease compared to the second quarter of the previous year (7.8\% in 2016). The employment practice without the completion of individual employment contracts (based on verbal agreements) is more common among male employees $(8.0 \%)$ than female employees $(5.0 \%)$. The largest shares of employees working only on verbal understanding are estimated to be in agriculture (38.4\%) and trade (16.1\%).

Each service system must be provided not only material - economically but also with wellprepared human resources. We find that, generally, the health services in the country are affected by the great mobility/exodus and the shortage of medical staff. In the past twenty years, more than $40 \%$ of health workers have left the health system. At national level, the number of doctors decreased from 16,199 in 1996 to approximately 10,397 in 2015. The same phenomenon is found among the doctors of the Public Health Surveillance Service, in the case of hygienist doctors in the Occupational Health Service.

For a deeper understanding of this phenomenon, our study included the use of a qualitative questionnaire and in-depth interviews with hygienist doctors from the territorial public health centers. The interview data from the full research sample of 35 hygienist doctors in the district public health centers was structured according to: the age of the respondents (under 35, 35-60 and over 60); the length of their service (under 5, 5-35 and over 35); grade of specialization (superior, first category, second category and without category).

As a result of the analysis, the age of doctors from district PHC is $50.77 \pm 1.98$ years, Min $=27.0$ years and Max $=70.0$ years $(S D=11.76)$, the length of service is $24.97 \pm 2.24$ years, Min $=$ 1.0 years and Max $=45.0$ years, $(S D=13.27)$. Regretfully, doctors under the age of 35 were a minority $(14.3 \%)$, while the number of people of retirement age $(22.9 \%)$ is high. Doctors were asked if "the occupational health vision has changed following the workshop": those under 35 years responded positively in $80.0 \%$ of cases, those over 60 years - 75.0\% of cases and those between 35 60 years $-27,3 \%$ of cases. The current situation confirms the responsibility of the specialists for the daily problems encountered in the service of occupational health (see Figure 4).

The affirmative responses to the questions regarding the usefulness of knowledge for practical work were distributed as follows (see Figure 5):

- basic notions in occupational health $(\mathrm{OH}): 74.3 \%$ of cases $(60 \%$ among doctors aged $<35$ years, $62.5 \%$ among doctors aged $>60$ years, and 81.8\% among those aged 35-60 years);

- OH legislation: $62.9 \%$ of cases $(40 \%$ among doctors aged $<35$ years, $75 \%$ among doctors aged $>60$ years, and $63.6 \%$ among those aged $35-60$ years);

- components of the $\mathrm{OH}$ structure: $37.1 \%$ of cases (40\% among doctors aged <35 years, $25 \%$ among doctors aged $>60$, and $40.9 \%$ among those aged $35-60$ years);

- $\mathrm{OH}$ tasks: $54.3 \%$ of cases $(60 \%$ among doctors aged $<35$ years, $37.5 \%$ among doctors aged $>$ 60 , and $59.1 \%$ among those aged $35-60$ years);

- OH activities: $51.5 \%$ of cases (80\% among doctors aged $<35$ years, $25 \%$ among doctors aged $>$ 60 , and $54.5 \%$ among those aged $35-60$ years); 
Analyzing the answers, we found the responsibility (in the anonym questionnaire) of the doctors in the 35-60 age group with valid statistical representation.

Figure. 4. The distribution of the answers to the first question, "the occupational health vision has changed following the workshop" and the respondents' age, $\%$.

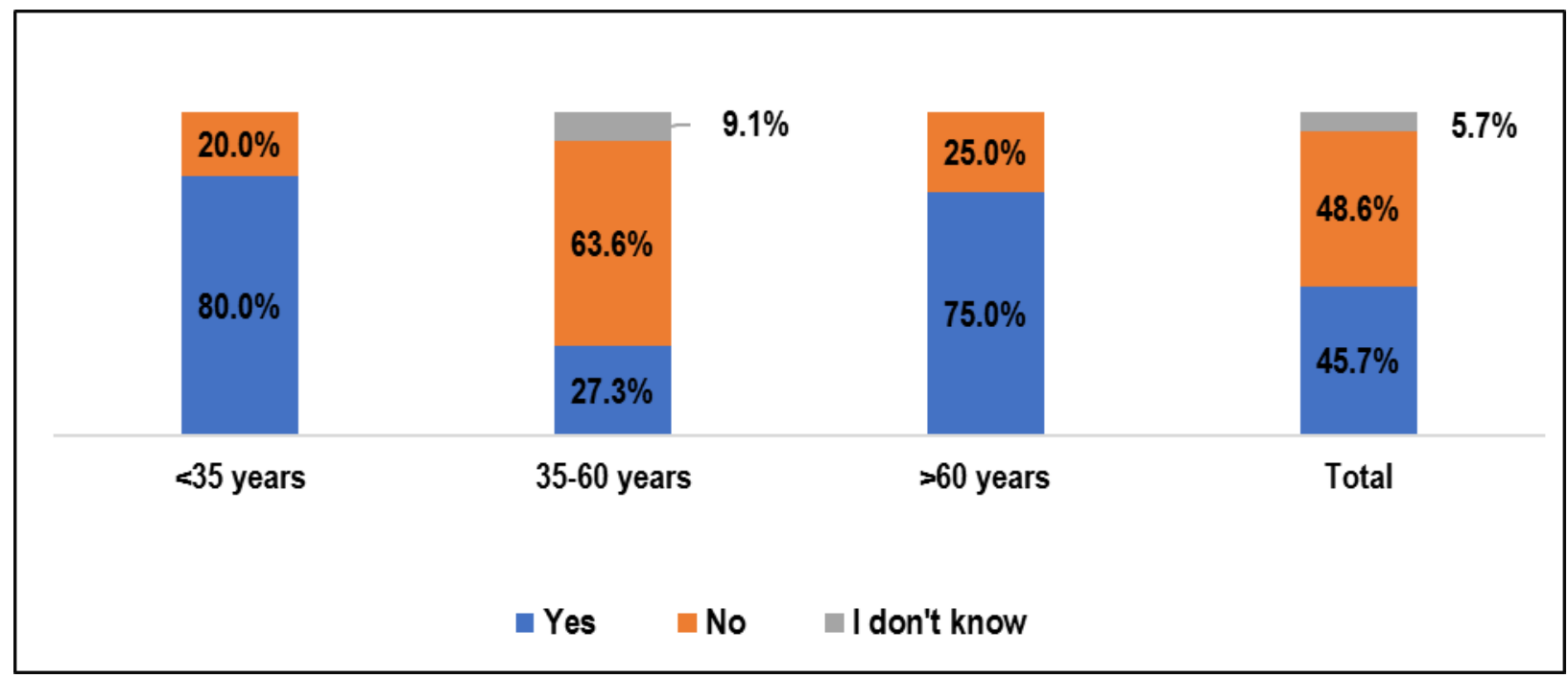

Figure 5. Distribution of responses on utility and information needs following training courses and approached items, \%.

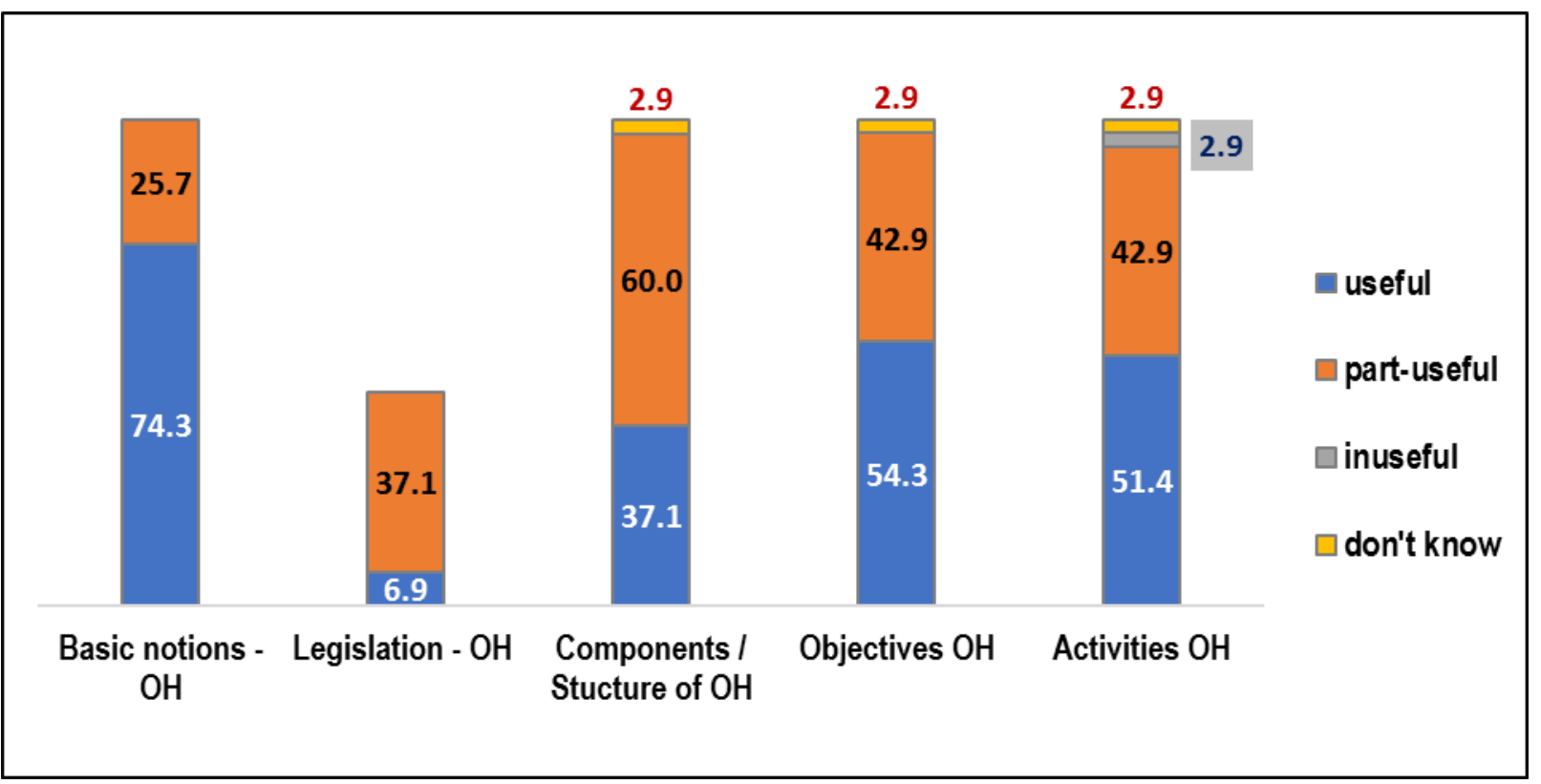

On the other hand, to the question about "the usefulness of information for international law", the answers were distributed in the following way: useful - 48.6\%; partially useful - 42.9\%; useless $-5.7 \%$ and do not know $-2.9 \%$ of cases. 
Further to the "usefulness of the information for national legislation", the answers were as follows: useful - 65,7\%; partially useful - 34,3\%. The objectivity of these questions was presented by the respondents aged 35-60, with representative statistical validity.

The survey also included the identification of those services that intersect/interfere with the work of medical hygiene specialist at the local level. According to their frequency, these were reported as follows: ecologic inspectorate - 34.3\%; labor inspection -14.3\%; agricultural department - 11.4\%; local public administration - 8.3\%, etc.

Regretfully, doctors specialized in occupational diseases, doctors/physicians working in companies or medical examination committees of employees, physicians and others were not mentioned. As it is known, professional diseases have not been diagnosed for three years, in the republic.

In this context, we investigated what training topic (which requires a more detailed or indepth preparation) would be more welcomed among the specialists (see Figure 5).

The first place was shared by the national legislation and normative acts (nominated by 91.4\% of the respondents) and the risk factors in the occupational environment (nominated by an equal percentage). The second place was occupied by the stress at work (topic advanced by $85.7 \%$ of the respondents). The third priority, with an insignificant difference, was the organization of occupational health service (chosen by $82.9 \%$ ) and familiarization with ergonomic methods in OHS (indicated by $82.4 \%$ ).

According to priorities the topics have been hierarchized as follows: experiences and international normative acts (68.6\%); supervision of enterprises where a diagnosis of occupational disease is suspected (74.3\%); research of occupational diseases (77.1\%); medical-professional rehabilitation of employees $(80.0 \%$ ) (see Figure 6).

Figure. 6. Distribution of responses on the usefulness and necessity of information following training courses and addressed items, $\%$.

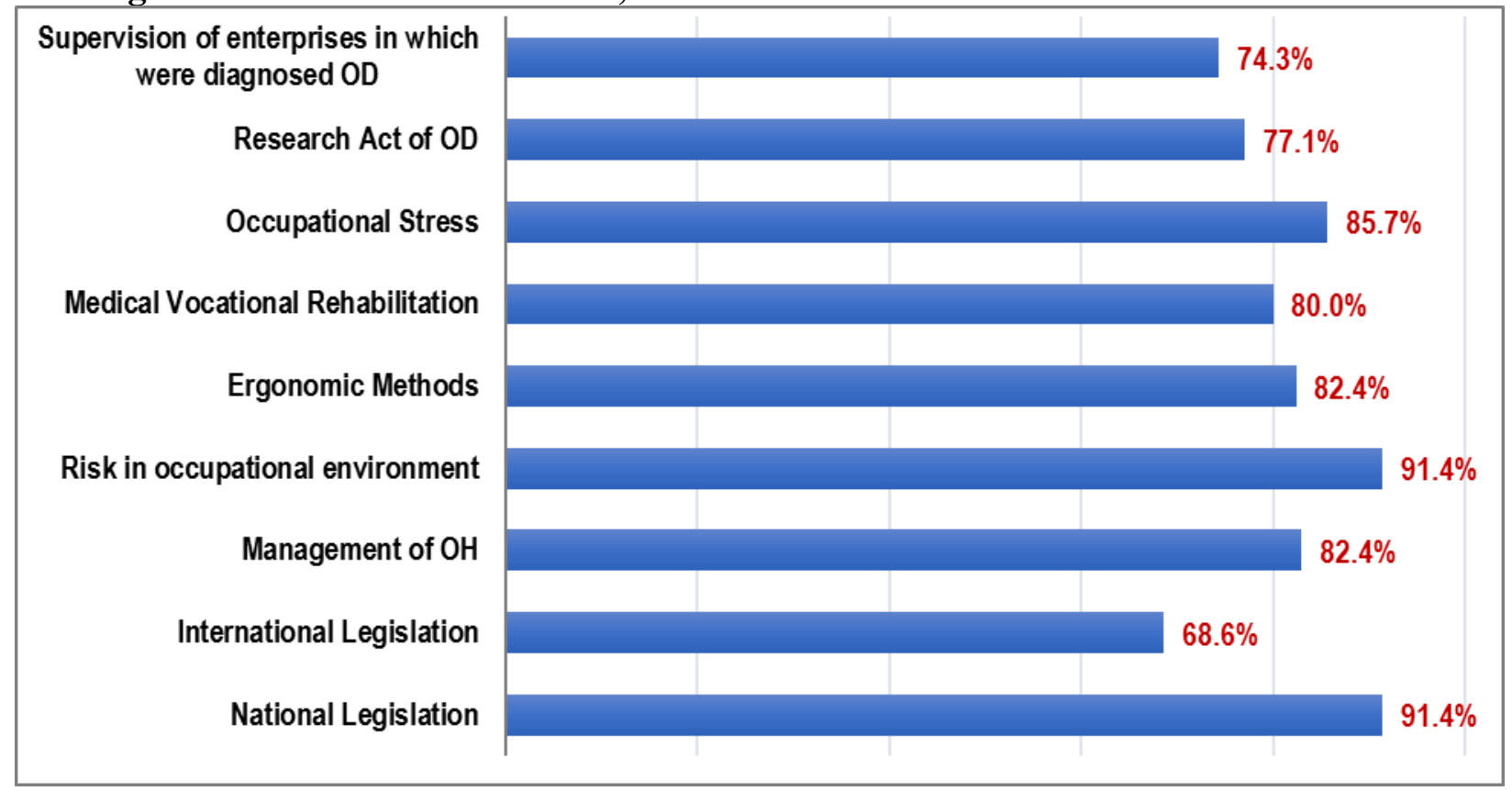


The participants to study were also questioned about their interests in dedicated workshops. Their suggestions include interactive dialogue (submitted by $74.3 \%$ of the respondents); distribution of didactic materials (expressed by $71.4 \%$ ); the utility of the material in practice (supported by $65.7 \%)$.

Today, the welfare of industrialized and developing countries is based on technologies that require chemicals in the occupational environment. While these chemicals are extremely valuable and useful, their production, use, and disposal can be dangerous to human health and the environment. In spite of stringent legislative controls in the EU-27, and the implementation of many voluntary measures by enterprises, annual appraisals indicate that 167,000 workers die due to working conditions. More than $95 \%$ of these deaths are caused by occupational diseases, and half of these deaths are attributable to exposure to chemical and toxic chemicals. Among the main causes are long-term exposures that lead to the development of work-related cancers.

According to EU-OSHA, chemicals products and hazardous chemicals or other materials used in the workplace can cause up to 70,000 deaths per year in the EU. Most of them are from long-term exposure and asbestos still contributes significantly.

Occupational health services confront important changes as a result in the occupational environment, in the health and security concepts, in legislation. In order to achieve a high quality of OHS at a reasonable cost, it is important to prepare a "National Occupational Profile", which will systematize the occupational concept with the help of standard indicators and present them with regularity (5 years, 10 years, 15 years, etc.).

National Occupational Profile is often performed based on the concept of critical thinking. The concept of preventive thinking is presented to manage health services at the workplace (Godderis et al., 2012).

\section{Conclusions}

The findings reveal a stringent need to develop a new strategy on the health and safety of employees at the workplace. This reform will have to consolidate the given area, to harmonize the Internal Legislation with International Labor Organization and World Health Organization conventions in the given field, and to rely on the main directions set by the International Commission on Occupational Health (ICOH).

The achievement of the objectives of occupational medicine is based on the predominant prophylactic feature of this complex discipline, which will be carried out through the systematic supervision with adequate means of the working conditions and health status of the employees in order to identify the new professional risks and methods of combating them. The Occupational Medicine/Occupational Health Services requires the orientation towards teamwork of the specialists in the field of health and safety at work; it is necessary to coordinate well all the services responsible for the health status of the working age population.

The creation of the Occupational Medicine/Occupational Health Service will contribute to improvement of health-care assistance to workers, working conditions, health of employees and of working-age population, by diminishing occupational diseases, morbidity with temporary incapacity to work, general morbidity, work trauma, working-age mortality, and therefore it will contribute to the essential growth of the national economy.

The creation and implementation of the Occupational Medicine/Occupational Health Service will allow in perspective that the policy and the strategy of health and safety at work will no longer present separate activity fields but a whole one, which, within the framework of national policy and strategy, will bring together intersectoral efforts both in legislative and institutional plans. 


\section{References}

1. Froneberg, B. and Timm, S. (CWorld Health Organization Regional Office for Europe, 2012. Country Profile of Occupational Health System in Germany. Available at: <http://www.euro.who.int/_data/assets/pdf_file/0010/178957/OSH-Profile-Germany.pdf?ua=1 $>$ [Accessed 19 October 2017]

2. Godderis, L., Johannik, K., Mylle, G., Bulterys, S., Moens, G., 2014. Epidemiological and performance indicators for occupational health services: a feasibility study in Belgium. BMC health services research, 14, pp.410-419, [online] Available at: <https://bmchealthservres.biomedcentral.com/articles/10.1186/1472-6963-14-410> [Accessed 19 October 2017].

3. Godderis, L., Vanhaecht, K., Masschelein, R., Sermeus W., Veulemans H., 2004. Prevention pathways: application of the critical path methodology in occupational health services. Journal of occupational and environmental medicine, 46(1), pp.39-47. Available at: <https://pdfs.semanticscholar.org/4152/0bca779b45a22beaf5d69d104b538462ed91.pdf> [Accessed 19 October 2017].

4. Harrison, J., Dawson, L., 2016. Occupational Health: Meeting the Challenges of the Next 20 Years. Safety and health at work, 7(2), pp.143-149. Available at: <https://www.ncbi.nlm.nih.gov/pmc/articles/PMC4909849/> [Accessed 19 October 2017].

5. Macdonald, E., Sanati, K., 2010. Occupational health services now and in the future: the need for a paradigm shift. Journal of occupational and environmental medicine, 52(12), pp.12731277. Available at: <https://www.ncbi.nlm.nih.gov/pubmed/21750477> [Accessed 19 October 2017].

6. Michalak J., 2002. Quality assessment in occupational health services: a review. International journal of occupational medicine and environmental health, 15(2), pp.165-171. Available at: <https://www.ncbi.nlm.nih.gov/pubmed/12216774> [Accessed 19 October 2017].

7. Rantanen, J., Kim R. OWorld Health Organization Regional Office for Europe, 2012. Situation Analysis and Recommendations for Stewardship on Workplace Health Promotion in Poland. [online] Available at: <http://www.euro.who.int/en/countries/poland/publications/situationanalysis-and-recommendations-for-stewardship-on-workplace-health-promotion-in-poland > [Accessed 19 October 2017].

8. Turcanu, G., Domente, S., Buga, M., Richardson, E., 2012. Republic of Moldova: health system review. Health systems in transition, 14(7), pp. 1-151. [online] Available at: <https://www.ncbi.nlm.nih.gov/pubmed/23211662> [Accessed 19 October, 2017].

9. ${ }^{* * *}$ International Labour Organization \& Ministry of Labour, Social Protection and Family of the Republic of Moldova, 2011. National Occupational Safety and Health Profile Republic of Moldova. Available at: <http://www.ilo.org/wcmsp5/groups/public/---ed protect/---protrav/--safework/documents/policy/wcms_208206.pdf> [Accessed 19 October 2017].

10. ${ }^{* * * *}$ Ministry of Social Affairs and Health of Finland, 2006. National Occupational Safety and Health Profile of Finland. Helsinki: Helsinki University Printing House. Available at: $<$ http://www.ilo.org/wcmsp5/groups/public/---ed_protect/---protrav/--safework/documents/policy/wcms_179869.pdf> [Accessed 19 October 2017]. 